\title{
Measurement of Bone Mineral Density from Different Race of Elderly Population in Mianyang, China
}

\author{
Xiao-Dong Penga ${ }^{1}$, Chang-Quan Huang ${ }^{2 *}$, Lai Song ${ }^{1}$, Yan Cheng ${ }^{2}$, Xue-Mei Wei ${ }^{2}$ and Qing-Xiu Liu ${ }^{2}$ \\ ${ }^{1}$ Department of Oncology, The Second People's Hospital of Chengdu, Chengdu 610017, Sichuan, China \\ ${ }^{2}$ Department of Geriatrics, The Third Hospital of Mianyang, Mianyang 621000, Sichuan, China
}

\begin{abstract}
Background: To investigate the relationship between bone mineral density (BMD) and race in the different race of old population living in Mianyang, a region in West China.
\end{abstract}

Methods: By dual energy X-ray absorptiometry, BMD was detected in lumbar spine, femoral neck and femoral trochanter of 5039 cases living in urban, suburban and rural areas (1895 cases of male, 3144 cases of female). BMD was also compared among different races including Han, Tibetan, Qiang and Hui.

Results: In the Mianyang, whether male or female, BMD in Han was significantly higher than that in Tibetan, Qiang and Hui $(P<0.05)$. Furthermore, BMD in Hui was also greater than that in Tibetan and Qiang while BMD in Qiang was dramatically higher than that in Tibetan $(P<0.05)$.

Conclusion: Our study demonstrates that BMD is closely associated with race in aged people in Mianyang, China.

Keywords: Race; Bone mineral density; Dual energy X-ray absorptiometry; Relationship

Abbreviations: BMD: Bone Mineral Density; FN: Femoral Neck; SD: Standard Deviation; WHO: World Health Organization

\section{Introduction}

Osteoporosis is the decrease of bone mineral content in the whole body and the degradation of bone microstructure, a degenerative disease of bone which leads to the increase of bone fragility and fracture risk [1,2]. Bone mineral density (BMD) is often used as criteria for diagnosis and therapeutic efficacy for osteoporosis in clinic. There are many detection methods of BMD, in which the dual energy X-ray bone density detection, whose test results are the gold standard for the diagnosis of osteoporosis, is widely used and recognized [3-6]. With the increase of population aging, osteoporosis has become a public health problem with a high incidence, a wide range of people, complex risk factors and serious consequences [7-11]. There are many risk factors for osteoporosis, including age, bad habits and so on, but the relationship between osteoporosis and race remains unclear [7-16]. The purpose of this study, therefore, was to analyze the BMD data in the Han, Tibetan, Qiang and Hui people of Mianyang city and to further explore the relationship between osteoporosis and race.

\section{Materials and Methods}

\section{Detected objects}

The detected objects were 5039 (1895 male and 3144 female) volunteers aged over 50 years from urban, suburban and rural areas of Mianyang, and their races covered Han, Tibetan, Qiang and Hui. The study was also approved by the Ethics Committee of the Third People's Hospital of Mianyang City.

\section{Detection methods and diagnostic criteria}

BMD of the lumbar spine 1-4 (L1-L4), left femoral neck (FN) and Ward's Triangle were detected using dual energy X-ray bone density detector (American General Co.) according to the manufacturer's instructions and the previous studies [3-6,17].

\section{Statistical analysis}

Statistical analysis was performed with the SPSS software system (SPSS for Windows, version 13.0; SPSS Inc., Chicago, IL) The measurement data were expressed as mean \pm SD. Moreover, the comparisons between different groups were examined by with Student's $\mathrm{t}$ test or one-way analysis of variance followed by post hoc tests when appropriate. A significant difference was defined as $\mathrm{p}<0.05$.

\section{Results}

According to age, BMD in the male was compared among different races

In different age groups (50-59 years old, 60-69 years old, 70-79 years old, above 80 years old), BMD in male was compared among different races. Our results showed that the level of BMD in Han people from different age groups was higher than that in Hui, Tibetan and Qiang people. In addition, BMD in Hui was greater than that in Qiang and Tibetan; BMD in Qiang was remarkably higher than that in Tibetan $(\mathrm{P}<0.05)$ (Table 1).

\section{According to age, BMD in the female was compared among} different races

In different age (50-59 years old, 60-69 years old, 70-79 years old, above 80 years old), BMD in female was compared among different race. The study revealed that in different age groups, BMD in Han people was higher than that in Hui, Tibetan and Qiang people. Furthermore, BMD in Hui was more than that in Qiang and Tibetan while BMD in Qiang was greater than that in Tibetan $(\mathrm{P}<0.05)$ (Table 2).

*Corresponding author: Chang-Quan Huang, Department of Geriatrics, The Third Hospital of Mianyang, Mianyang 621000, Sichuan, China, Tel: 86-816-2372300, E-mail: huangcq2016@163.com

Received October 10, 2017; Accepted October 17, 2017; Published October 23 2017

Citation: Penga X, Huang C, Song L, Cheng Y, Wei X, et al. (2017) Measurement of Bone Mineral Density from Different Race of Elderly Population in Mianyang, China. J Gerontol Geriatr Res 6: 451. doi:10.4172/2167-7182.1000451

Copyright: @ 2017 Penga X, et al. This is an open-access article distributed under the terms of the Creative Commons Attribution License, which permits unrestricted use, distribution, and reproduction in any medium, provided the original author and source are credited. 


\begin{tabular}{|c|c|c|c|c|}
\hline $\begin{array}{l}\text { Age } \\
\text { group }\end{array}$ & $\mathrm{n}$ & $L_{1}-L_{4}$ & $\begin{array}{c}\text { Left femoral neck } \\
\text { (FN) }\end{array}$ & Ward's Triangle \\
\hline \multicolumn{5}{|c|}{$50-59$ years old } \\
\hline Han & 178 & $0.912 \pm 0.113$ & $0.820 \pm 0.159$ & $0.795 \pm 0.101$ \\
\hline Tibetan & 8 & $0.813 \pm 0.207^{*}$ & $0.763 \pm 0.138^{*}$ & $0.722 \pm 0.241^{*}$ \\
\hline Qiang & 9 & $0.875 \pm 0.196^{\#}$ & $0.841 \pm 0.245^{\#}$ & $0.743 \pm 0.271^{\#}$ \\
\hline Hui & 7 & $0.888 \pm 0.212^{*}$ & $0.827 \pm 0.279^{\#}$ & $0.788 \pm 0.243 @$ \\
\hline \multicolumn{5}{|c|}{$60-69$ years old } \\
\hline Han & 429 & $0.893 \pm 0.106$ & $0.807 \pm 0.142$ & $0.773 \pm 0.096$ \\
\hline Tibetan & 15 & $0.745 \pm 0.182^{\circ}$ & $0.725 \pm 0.191^{*}$ & $0.685 \pm 0.173^{*}$ \\
\hline Qiang & 18 & $0.812 \pm 0.274 ;$ & $0.814 \pm 0.238$ & $0.695 \pm 0.169$; \# \\
\hline Hui & 16 & $0.825 \pm 0.168^{\#}$ & $0.783 \pm 0.251^{\#}$ & $0.742 \pm 0.216^{\#, @}$ \\
\hline \multicolumn{5}{|c|}{$\mathbf{7 0 - 7 9}$ years old } \\
\hline Han & 575 & $0.848 \pm 0.127$ & $0.791 \pm 0.185$ & $0.743 \pm 0.089$ \\
\hline Tibetan & 17 & $0.729 \pm 0.131^{*}$ & $0.698 \pm 0.170^{*}$ & $0.637 \pm 0.212^{*}$ \\
\hline Qiang & 24 & $0.772 \pm 0.168^{*}, \#$ & $0.787 \pm 0.139^{\#}$ & $0.672 \pm 0.173^{*}, \#$ \\
\hline Hui & 16 & $0.809 \pm 0.226^{\#}$ & $0.758 \pm 0.281^{\#}$ & $0.731 \pm 0.194^{\#}$ \\
\hline \multicolumn{5}{|c|}{80 -years-old } \\
\hline Han & 548 & $0.788 \pm 0.113$ & $0.764 \pm 0.107$ & $0.743 \pm 0.071$ \\
\hline Tibetan & 15 & $0.716 \pm 0.152^{*}$ & $0.688 \pm 0.176^{*}$ & $0.624 \pm 0.201^{*}$ \\
\hline Qiang & 13 & $0.726 \pm 0.193^{\#}$ & $0.720 \pm 0.115^{\#}$ & $0.660 \pm 0.218^{\#}$ \\
\hline Hui & 7 & $0.785 \pm 0.209^{*}$ & $0.784 \pm 0.262 \#, @$ & $0.701 \pm 0.271^{\# @ @ ~}$ \\
\hline
\end{tabular}

Compared with Han, ${ }^{*} \mathrm{P}<0.05,{ }^{*} \mathrm{P}<0.01$; Compared with Tibetan, \#P<0.05, \#P< 0.01 ; Compared with Qiang, @P $<0.05$, @@P $<0.01$

Table 1: Stratified by age, BMD in different men was compared $\left(\mathrm{g} / \mathrm{cm}^{2}\right.$, mean $\left.\pm \mathrm{SD}\right)$

\begin{tabular}{|c|c|c|c|c|}
\hline Age group & $\mathbf{n}$ & $L_{1}-L_{4}$ & $\begin{array}{l}\text { Left femoral } \\
\text { neck (FN) }\end{array}$ & Ward's Triangle \\
\hline \multicolumn{5}{|c|}{$50-59$ years old } \\
\hline Han & 612 & $0.839 \pm 0.113$ & $0.781 \pm 0.068$ & $0.746 \pm 0.079$ \\
\hline Tibetan & 35 & $0.756 \pm 0.165^{*}$ & $0.713 \pm 0.184^{*}$ & $0.709 \pm 0.293^{*}$ \\
\hline Qiang & 21 & $0.793 \pm 0.158^{*}, \#$ & $0.731 \pm 0.243^{*}$ & $0.715 \pm 0.264^{*}$ \\
\hline Hui & 19 & $0.819 \pm 0.127^{\#}$ & $0.776 \pm 0.297^{\#, @ ~}$ & $0.738 \pm 0.261^{\#}$ \\
\hline \multicolumn{5}{|c|}{$60-69$ years old } \\
\hline Han & 493 & $0.795 \pm 0.140$ & $0.748 \pm 0.117$ & $0.728 \pm 0.135$ \\
\hline Tibetan & 79 & $0.715 \pm 0.196^{* *}$ & $0.689 \pm 0.205^{* *}$ & $0.632 \pm 0.212^{* *}$ \\
\hline Qiang & 54 & $0.768 \pm 0.152^{* \#}$ & $0.716 \pm 0.317^{* \text { \#\# }}$ & $0.666 \pm 0.237^{* *+*}$ \\
\hline Hui & 58 & $0.799 \pm 0.121^{\# \#}$ & $0.742 \pm 0.261^{\#}$ & $0.721 \pm 1.079^{\# \#}$ \\
\hline \multicolumn{5}{|c|}{$70-79$ years old } \\
\hline Han & 933 & $0.748 \pm 0.097$ & $0.736 \pm 0.095$ & $0.718 \pm 0.081$ \\
\hline Tibetan & 56 & $0.723 \pm 0.185^{*}$ & $0.669 \pm 0.222^{* *}$ & $0.623 \pm 0.286^{*}$ \\
\hline Qiang & 57 & $0.737 \pm 0.201$ & $0.705 \pm 0.266^{*}, \#$ & $0.653 \pm 0.244^{*}, \#$ \\
\hline Hui & 76 & $0.753 \pm 0.164^{\#}$ & $0.729 \pm 0.138^{*}, \#$ & $0.701 \pm 0.358^{*, \#}$ \\
\hline \multicolumn{5}{|c|}{ 80-years-old } \\
\hline Han & 492 & $0.725 \pm 0.128$ & $0.736 \pm 0.113$ & $0.728 \pm 0.147$ \\
\hline Tibetan & 51 & $0.709 \pm 0.138$ & $0.650 \pm 0.276^{*}$ & $0.623 \pm 0.189^{*}$ \\
\hline Qiang & 44 & $0.728 \pm 0.337$ & $0.667 \pm 0.283^{*}$ & $0.635 \pm 0.244^{*}$ \\
\hline Hui & 64 & $0.739 \pm 0.258$ & $0.729 \pm 0.138^{\#, @ ~}$ & $0.697 \pm 0.073^{\#, @}$ \\
\hline
\end{tabular}

Table 2: Stratified by age, comparison of BMD in different women $\left(\mathrm{g} / \mathrm{cm}^{2}\right.$, mean $\pm \mathrm{SD}$ ).

\section{Discussion}

In this study, BMD in Han, Tibetan, Qiang and Hui people living in Mianyang was compared. According to their gender and age, our results suggested that BMD in Han people was higher than that in Hui, Tibetan and Qiang people; BMD in Hui was more than that in Qiang and Tibetan; BMD in Qiang was greater than that in Tibetan.

BMD is an important indicator of bone quality, and it is used as a clinical index for the diagnosis of osteopenia and osteoporosis [18].
The diagnostic criteria for osteopenia and osteoporosis are generally diagnosed with the comparison of peak bone mass in the same race group, and the mean values of the BMD in peak bone mass and the people be tested is known as $\mathrm{T}$ values. According to the diagnostic criteria recommended by WHO: The $\mathrm{T}$ value $\geq-1.0$ (standard deviation, $\mathrm{SD}$ ) was diagnosed as normal bone mass, $\mathrm{T}$ value between $-1.0 \mathrm{SD}$ and $-2.5 \mathrm{SD}$ was diagnosed as osteopenia and $\mathrm{T}$ value $\leq-2.5$ $\mathrm{SD}$ was diagnosed as osteoporosis. But this standard is formulated in accordance with the western developed countries, not all countries in the world adopt the above standards. The standard that China's most industry experts recommend is different from WTO: T value between $-1.0 \mathrm{SD}$ and $-2.0 \mathrm{SD}$ was diagnosed as osteopenia and $\mathrm{T}$ value $\leq-2.0 \mathrm{SD}$ was diagnosed as osteoporosis. The diagnostic criteria for osteopenia and osteoporosis were higher than that of WHO, but the specificity was poor. Not all countries in the world adopt WHO standards, in addition to considering the living environment and the level of the relevant, the national factors are also considered. BMD of different national groups have differences, which have been recognized by level of development and national medical standards. [18-20]. At the same time, reports about the prevalence of osteoporosis were very different, and this difference may also be related to the race groups in the population.

In addition to suggest that BMD and race are related, the study has following significance. First: the results of this study showed that the relationship between the BMD and the four different race groups in Mianyang and BMD of the order from high to low is Han, Hui, Qiang and Tibetan. Second, although people in Mianyang live in the same district, different nationality lives relatively concentrate (For example, there are Hui Autonomous Township, Qiang Autonomous County and Tibetan Autonomous Township). The Hui Autonomous Township and the Han nationality have no significant difference in altitude and climate, Qiang Autonomous County's elevation is higher than that of Han habitat (the temperature is relatively lower), and the Tibetan Autonomous township seats near the Northwest Plateau of Sichuan Province. BMD differences between different race groups may be related to the climate and elevation of the living area, which can be confirmed using the same race groups living in different environment [16]. Third, the living habits of different nation are different. Han population living habit was no special, the Hui people are generally vegetarian, Qiang and Tibetan people eat more beef and mutton. Differences in BMD between different races may be lifestyle-related.

\section{Limitations}

There are some limitations in this article. Firstly, for epidemiological investigation, sample size was small. But, in Chinese, people are not paying enough attention to prevention and treatment of osteoporosis, fewer people have bone mineral density tests, therefore, it was difficult to conduct a large sample of related studies and no participant was exclude. Secondly, there is a big difference between the numbers of subjects in the compared groups (Han $=178$, Tibetan $=8$, Qiang=9, Hui=7), this might affect the results of the analysis; however, they were minority and it was difficult Get more Han, Tibetan, Qiang participants.

\section{Conclusion}

In the study, BMD of four race groups in Mianyang were compared, the results showed that $\mathrm{BMD}$ is race-related, and national differences may be related to genetics, living area and their diet. Factors caused BMD differences in different races need to be further confirmed.

\section{Acknowledgements}

This work was supported by the Science Technology and Graveness Project of Sichuan Province (2013FZ0051) and the Illustrious Youth Specialist Project of 
Citation: Penga X, Huang C, Song L, Cheng Y, Wei X, et al. (2017) Measurement of Bone Mineral Density from Different Race of Elderly Population in Mianyang, China. J Gerontol Geriatr Res 6: 451. doi:10.4172/2167-7182.1000451

Sichuan Province (2012JQ0051) and Postdoctoral Science Foundation of China and Sichuan Province (2013M542282) and the Science Technology Project of Chengdu City (2015-HM01-00275-SF).

\section{References}

1. Gupta AK, Shah N, Thakar AB (2012) Effect of Majja basti (therapeutic enema) and Asthi shrinkhala (Cissus quadrangularis) in the management of osteoporosis (Asthi-Majjakshaya). Ayu 33: 110-113.

2. Sunyecz $\mathrm{J}$ (2008) Optimizing dosing frequencies for bisphosphonates in the management of postmenopausal osteoporosis: Patient considerations. Clin Interv Aging 3: 611-627.

3. López E, Casajús JA, Ibarz E (2015) Application of a model based on dualenergy $\mathrm{X}$-ray absorptiometry and finite element simulation for predicting the probability of osteoporotic hip fractures to a sample of people over 60 years. Proc Inst Mech Eng H 229: 369-385.

4. Mazess RB, Trempe JA, Bisek JP, Hanson JA, Hans D (1991) Calibration of dual-energy x-ray absorptiometry for bone density. J Bone Miner Res 6: 799806 .

5. Maksoud C, Iruzun C, Silva C (2009) Bone density analysis using dual energy $\mathrm{x}$-ray (DXA) bone absorptiometry in clinical investigation. J Clin Densitom 12: 383.

6. Simmons A, Barrington S, O'Doherty MJ, Coakley AJ (1995) Dual energy X-ray absorptiometry normal reference range use within the UK and the effect of different normal ranges on the assessment of bone density. $\mathrm{Br} \mathrm{J}$ Radiol 68 : 903-909.

7. Ohta $H$, Solanki J (2015) Incorporating bazedoxifene into the treatment paradigm for postmenopausal osteoporosis in Japan. Osteoporos Int 26: 849863.

8. Svedbom A, Hernlund E, Ivergard M, Compston J, Cooper C, et al. (2013) Osteoporosis in the European Union: A compendium of country-specific reports. Arch Osteoporos 8: 137.

9. Body JJ, Bergmann P, Boonen S, Devogelaer JP, Goemaere S, et al.
(2010) Evidence-based guidelines for the pharmacological treatment of postmenopausal osteoporosis: A consensus document by the Belgian Bone Club. Osteoporos Int, 21: 1657-1680.

10. Kanis JA, Burlet N, Cooper C, Delmas PD, Reginster JY, et al. (2008) European guidance for the diagnosis and management of osteoporosis in postmenopausal women. Osteoporos Int 19: 399-428.

11. Tella SH, Gallagher JC (2014) Prevention and treatment of postmenopausal osteoporosis. J Steroid Biochem Mol Biol, 142: 155-170.

12. Leppänen OV, Sievanen H, Jokihaara J, Pajamaki I, Kannus $P$, et al. (2008) Pathogenesis of age-related osteoporosis: impaired mechano-responsiveness of bone is not the culprit. PLoS One 3: e2540.

13. Sharma JB, Newman MR, Smith RJ (1994) Depot medroxyprogesterone acetate and osteoporosis. Smoking may explain findings. BMJ 308: 717.

14. Chen H, Liu N, Xu X, Qu X, Lu E (2013) Smoking, radiotherapy, diabetes and osteoporosis as risk factors for dental implant failure: A meta-analysis. PLoS One 8: e71955.

15. Brook JS, Balka EB, Zhang C (2012) The smoking patterns of women in their forties: their relationship to later osteoporosis. Psychol Rep 110: 351-362.

16. Chi XX, Zhang $T$ (2013) The effects of soy isoflavone on bone density in north region of climacteric Chinese women. J Clin Biochem Nutr 53: 102-107.

17. Hosoi T (2015) On 2015 Guidelines for prevention and treatment of osteoporosis. Diagnostic criteria of primary osteoporosis and the criteria for pharmacological treatment. Clin Calcium 25: 1279-1283.

18. Kling JM, Clarke BL, Sandhu NP (2014) Osteoporosis prevention, screening and treatment: A review. J Womens Health (Larchmt) 23: 563-572.

19. Eastell R (2011) Guidelines for management of male osteoporosis. Bone 48 : S59.

20. Schnatz PF, Marakovits KA, Dubois M, O'Sullivan DM (2011) Osteoporosis screening and treatment guidelines: Are they being followed? Menopause 18 1072-1078. 